\title{
Electrochemical Impedance Spectroscopy of Dodecylsulphate Doped Polypyrrole Films in the Dark and Under Illumination
}

\author{
Milena Martini ${ }^{\text {a }}$,Tullio Matencio ${ }^{\text {b }}$, Nicolás Alonso-Vante ${ }^{\mathrm{c}}$, Marco-Aurelio De Paoli ${ }^{* \mathrm{~d}}$ \\ ${ }^{a}$ Departamento de Física Aplicada, Instituto de Física, Universidade de São Paulo, \\ CP 66318, 05315-970, São Paulo - SP, Brazil \\ ${ }^{b}$ Departamento de Química, ICEx, Universidade Federal de Minas Gerais, CP 702, 31270-901, Belo Horizonte - MG, Brazil \\ ${ }^{c}$ UMR-CNRS 6503, Universite de Poitiers, 40, Av. du Recteur Pineau, F-86022 Poitiers, France \\ ${ }^{d}$ Universidade Estadual de Campinas, Instituto de Química, CP 6154, 13081-970, Campinas - SP, Brazil
}

\begin{abstract}
Efeitos de morfologia, espessura, oxidação e iluminação dos filmes de polipirrol dopados com dodecilsulfato podem ser observados qualitativamente por EIS e consistem de variações de valores de resistências e capacitâncias de um circuito equivalente proposto, presentes nas interfaces e no interior do material. O circuito se ajusta bem para filmes sintetizados com densidade de carga de $190 \mathrm{mC} \mathrm{cm}{ }^{-2}$. Para filmes mais finos os valores calculados por espectroscopia de impedância eletroquímica (EIS) apresentam desvios provavelmente pela ausência de efeitos difusivos. A oxidação dos filmes causa uma diminuição geral da impedância em toda a faixa de freqüências medidas. Os efeitos de morfologia também são observados em todas as frequiências. Os efeitos de iluminação são reversíveis e aparecem, como esperado, apenas quando o polímero está na forma reduzida. A iluminação diminui a resistência interna e a capacitância de carga espacial e aumenta a resistência de transferência de carga e a capacitância de dupla camada.
\end{abstract}

The morphology, thickness, oxidation and illumination effects in dodecylsulphate doped polypyrrole films can be qualitatively observed by EIS and consist in variations of interfacial and bulk resistances and capacitances of a proposed equivalent circuit. The circuit well with the measured spectra of films obtained with $190 \mathrm{mC} \mathrm{cm}^{-2}$ of synthesis charge density. For thinner films the calculated values observed by electrochemical impedance spectroscopy (EIS) deviate probably due to the absence of diffusion effects. The oxidation of the films diminishes the total impedance over the entire frequency range. The morphology effects are also observed in the entire spectra. The illumination effects are reversible and are observed as expected only in the reduced form of the polymer. The illumination reduces the internal resistance and the space-charge capacitance and increases the charge transfer resistance and the double layer capacitance.

Keywords: conducting polymer, photoelectrochemistry, eletrochemical impedance spectroscopy

\section{Introduction}

Transport and transference processes of electronic and ionic charges of conducting polymers in contact with electrolytes are important for their applications in electrochemistry and photoelectrochemistry. Impedance spectroscopy permits to separate inductive, kinetic, diffusive and charge saturation processes, that take place within the material and at the active interfaces of the system. Different characteris-

Presented at the XI Simpósio Brasileiro de Eletroquímica e Eletroanalítica, Maragogi - AL, Brazil, April 5-9, 1999. Guest editor: Luis Alberto Avaca. tic relaxation times and their dependence upon an a.c. frequency of small amplitude applied to the system are the keys for a better comprehension of the phenomena involved in the synthesis of the films and the functioning and ageing of electro- and photoelectrochemical cells built with them.

Double layers with different electrical charges, such the Helmholtz double layer and the Gouy-Chapman region, and a space charge region are formed in a semiconductor electrolyte interface under appropriate conditions. At each of them a differential capacitance can be associated. When a space charge region with finite length, or depletion layer, is present in the semiconductor material, it determines the general system behaviour, and can be studied in details with the aid of EIS. 
Electrochemical impedance measurements for the determination of the flat band potential in photoelectrochemical systems based on polyaniline ${ }^{1}$, poly(3-methylthiophene $)^{2}$ and polypyrrole $^{3}$ films were already performed in our laboratory.

Many works are presented in the literature in which the electrochemical properties of polypyrrole and other conducting polymers synthesised in different conditions are studied by EIS. Bard and cols. ${ }^{4}$ have applied the technique for the first time with polypyrrole, PPy. The authors have shown that PPy films were porous to the electrolyte but electron transfer reactions can also occur at the polymer surface. The decreasing of admittance in potentials more negative than - 0.7 V vs SCE have confirmed the insulating nature of reduced PPy. The authors have used the model of a single pore to discuss the results obtained with impedance measurements around $+0.1 \mathrm{~V}$ vs SCE, neglecting the mass transfer effect.

Using the transmission line model presented by Rubinstein 5 , Albery and cols. ${ }^{6}$ have fitted the mobilities of the charge carriers in the polymer and of the counter-ions in the pores containing solution. Each line could have its own resistance. The results have shown that the two resistances were equal, indicating that the motion of the charge carriers in the polymer backbone and of the ions in the solution are coupled. The capacitance, distributed between the two lines is described by Feldberg7. The electron propagation may take place through molecular exchange reactions involving conformational changes of the polymer chains. But when the interchain transport is too fast, and the interchain hopping is the rate controlling process, this model cannot satisfactorily describe the experimental impedance data.

Waller and Compton ${ }^{8}$ studied PPy films $(0.025 \sim 0.15$ $\mathrm{mm}$ thick) electrosynthesised on Pt electrodes in the presence of $\mathrm{BF}_{4}$ - in acetonitrile, simultaneously by Electron Spin Resonance and EIS. They found that not only bipolarons but also polarons are involved in the conductivity of PPy. The complex plane plots of the films were dependent upon their doping degree. For applied potentials more negative than $0.0 \mathrm{~V}$ vs SCE two depressed semicircles were observed and they were attributed to the double layer at the PPy | Electrolyte interface (low frequency) and to the bulk PPy (high frequency). A charge saturation region (at low frequency), a depressed semicircle (at high frequency) and a straight line $\left(45^{\circ}\right)$ at intermediary frequencies were observed at potentials more positive than $0.0 \mathrm{~V} v s$ SCE. This line can be interpreted in terms of a reversible reaction involving the diffusion of charge-compensating counter-ions or of porous electrode. The depressed semicircles can be assigned to the roughness of the polymer surface.
By controlling the microscopic structure of polypyrrole, with chains growing perpendicularly to the substrate, Naoi and Osaka ${ }^{9}$ observed that the doping process is favoured in comparison to a film synthesised normally without structure control. The total impedance in the former case is smaller and diffusion controlled. More recently, Naoi and cols ${ }^{10}$. have demonstrated the influence of the columnar oriented structures of polypyrrole over the diffusion coefficient, D, and the limiting capacitance, CL, measured by EIS. Potentiostatically synthesised films of polypyrrole $\left(0.2 \mathrm{mC} \mathrm{cm}^{-2}\right)$ in solutions containing different concentrations of the surfactants dodecylsulphate, DS, and dodecylbenzenesulfonate, DBS, above and below the critic micellar concentration (c.m.c.), were used. They observed that $\mathrm{D}$ and $\mathrm{CL}$ values are not linear with respect to DS and DBS concentrations, but show an increase of 3 orders of magnitude near the c.m.c. The results were interpreted as an improved cation movement along the oriented columns in the polymer. Otero and Angulo ${ }^{11}$ have observed that the charge saturation capacitance, CCS, varies with the potential applied to PPy films obtained in the presence of $\mathrm{ClO}_{4}{ }^{-}$and it is also proportional to their thickness.

The determination of electronic and ionic exchange sites in addition to other diffusion and interfacial parameters was done by impedance measurements in PPy films in the form of modified electrodes (asymmetric configuration) and free membranes (symmetric configuration) ${ }^{12}$. The films were electropolymerized in an acetonitrile solution of pyrrole and tetraethylammonium tosylate and the measurements were performed in aqueous medium. It was found that the ionic diffusion coefficient is independent on the film thickness. This indicates that the film structure is maintained during the whole synthesis time. In addition, the authors observed that whatever the film thickness, the nature and concentration of the electrolyte, the electronic diffusion coefficient is always much higher than the ionic one.

The diversity of results obtained in these works and their possible interpretations is a result of the diversity of preparation methods and, at the same time, indicative of the great deal of effort devoted to describe the phenomena at the interfaces involving not only PPy but also other conducting polymers. The objectives of this work are to recognise and calculate parameters such as the polymer resistance, charge transfer in the redox process, ion diffusion in the polymer matrix, charge accumulation in the film and at the interfaces and loss of capacity as well as degradation of films obtained in different synthesis conditions and illuminated in an electrochemical cell. To the best of our knowledge, the photoelectrochemical impedance for polypyrrole is reported for the first time. 


\section{Experimental}

Synthesis of the films for scanning electronic microscopy

Films of polypyrrole doped with dodecylsulphate, PPyDS were synthesised galvanostatically on Pt substrates. Three films were synthesised with charge density of 290 $\mathrm{mC} \mathrm{cm}-2$ and current densities of $0.1,1.0$ and $5.0 \mathrm{~mA} \mathrm{~cm}^{-2}$. Other two films were synthesised with current density of $1.0 \mathrm{~mA} \mathrm{~cm}^{-2}$ and charge densities of 600 and $1200 \mathrm{mC} \mathrm{cm}^{-2}$. The samples were metalized by sputtering of $\mathrm{Au} / \mathrm{Pd}$ before the measurements in a JEOL JSM T-300 Scanning Electronic Microscope operating at $20 \mathrm{kV}$.

\section{Synthesis of the films for impedance measurements}

Four films of polypyrrole doped with dodecylsulphate, PPy-DS, were synthesised galvanostatically on Pt disks $\left(0.125 \mathrm{~cm}^{2}\right)$ in different conditions of applied charge and current densities (Table 1). The Pt electrodes were previously cleaned by electrochemical treatment in a $0.5 \mathrm{~mol} \mathrm{~L}^{-1}$ $\mathrm{H}_{2} \mathrm{SO}_{4}$ solution. The film thicknes were controlled by the synthesis charge and were measured with an Alpha-Step 200 Tencor Instruments profilometer. The films were conditioned by a series of oxidation / reduction cycles in the electrolyte prior to the impedance measurements.

Table 1. Current, J, and charge, Q, densities and time, $\mathrm{t}$ of synthesis used in the preparation of PPy-DS films and their measured thickness, L.

\begin{tabular}{ccccc}
\hline Film & $\mathrm{J} / \mathrm{mA} \mathrm{cm}^{-2}$ & $\mathrm{t} / \mathrm{s}$ & $\mathrm{Q} / \mathrm{mC} \mathrm{cm}^{-2}$ & $\mathrm{~L} / \mu \mathrm{m}$ \\
\hline 1 & 1,0 & 19 & 19 & 0,07 \\
2 & 0,1 & 190 & 19 & 0,15 \\
3 & 1,0 & 190 & 190 & 0,75 \\
4 & 0,1 & 1900 & 190 & 1,35 \\
\hline
\end{tabular}

\section{Electrochemical impedance measurements}

The impedance measurements of the samples in a three electrode cell arrangement were performed with a SI 1255 Schlumberger frequency analyser connected to a SI 1286 Schlumberger electrochemical interface and controlled by a computer. The measurements were made in the frequency range of $10 \mathrm{mHz}$ to $65 \mathrm{kHz}$ with amplitude perturbations of $5 \mathrm{mV}$ (rms). For the illumination of the films it we used an halogen lamp ( $44 \mathrm{~mW} \mathrm{~cm}^{-2}$ at the sample position) and a water filter. The cell was composed by a $1 \mathrm{~cm}^{2} \mathrm{Pt}$ counter electrode, SCE as reference electrode and a solution containing $0.5 \mathrm{~mol} \mathrm{~L}^{-1} \mathrm{KCl}$ and $5 \mathrm{mmol} \mathrm{L}^{-1} \mathrm{CrCl}_{3}$ acting as a redox mediator. The measurements were made at each potential $(-0.8,-0.65,-0.5,-0.35,0,+0.3$ and $+0.4 \mathrm{~V}$ vs ECS $)$ with the film in the dark and then under illumination. The results were fitted to proposed equivalent circuits by a non-linear last square algorithm 13 .

\section{Results and Discussion}

\section{General observations}

The cyclic voltammetry of a $190 \mathrm{mC} \mathrm{cm}^{-2}$ film (Figure 1) shows the applied potentials where the effect of illumination was observed (see left side of the figure). At those potentials the films are in the reduced state and can generate photocurrent in appropriate conditions ${ }^{14}$. In this case we can observe the kinetic control region with the presence of a depressed semicircle at higher frequencies, the diffusion control region with the presence of the Warburg section at intermediary frequencies and the limitation charge region at the lower frequencies. When the films are oxidised, the impedance of the systems is controlled basically by diffusion and at high oxidation conditions the impedance is controlled by charge saturation (Figure 2). The depressed semicircles seem to be caused by a distribution of parameter values due to surface heterogeneities and are commonly observed in measurements of systems containing polymers.

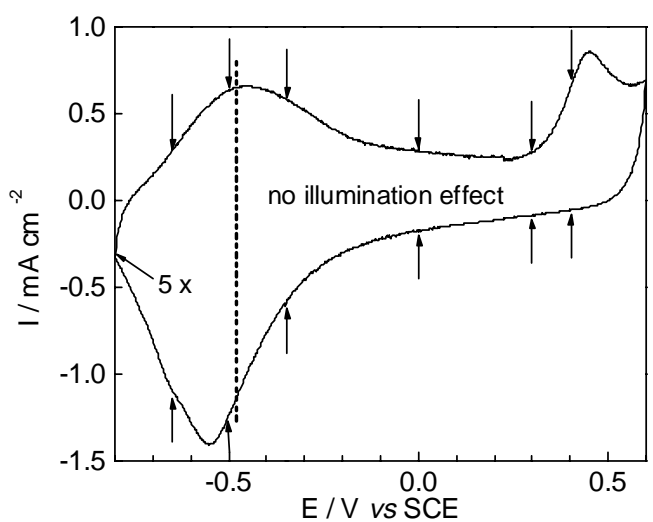

Figure 1. Cyclic voltammetry of a PPy-DS film $(J=0.1 \mathrm{~mA} \mathrm{~cm}-2$; $\left.\mathrm{Q}=190 \mathrm{mC} \mathrm{cm}^{-2}\right)$ synthesised on $\mathrm{Pt}\left(0.125 \mathrm{~cm}^{2}\right)$. Electrolyte: $\mathrm{KCl}$ $0.5 \mathrm{~mol} \mathrm{~L}^{-1}+\mathrm{CrCl}_{3} 5 \mathrm{mmol} \mathrm{L}-1 . \mathrm{CE}=\mathrm{Pt}, \mathrm{RE}=\mathrm{SCE}$. Scanning rate $\mathrm{v}=20 \mathrm{mV} \mathrm{s}^{-1}$. The arrows indicate the potentials at which EIS measurements were performed. At $-0.8 \mathrm{~V}$ " $5 \mathrm{x}$ " indicates the alternating measurements in the dark and under illumination.

\section{Oxidized PPy-DS}

Albery and cols 15 proposed equations to describe the responses of transmission line type for oxidised polypyrrole. In such case the polymeric electronic $\left(\mathrm{R}_{\mathrm{E}}\right)$ and ionic $\left(\mathrm{R}_{\mathrm{I}}\right)$ resistances and the resistance of the solution $\left(\mathrm{R}_{\mathrm{S}}\right)$ could be determined from the complex plane representation, using the following equations:

$\mathrm{R}_{\text {high }}=\mathrm{R}_{\mathrm{S}}+\mathrm{R}_{\infty}$

where

$\mathrm{R}_{\infty}^{-1}=\mathrm{R}_{\mathrm{E}}^{-1}+\mathrm{R}_{\mathrm{I}}^{-1}$ 


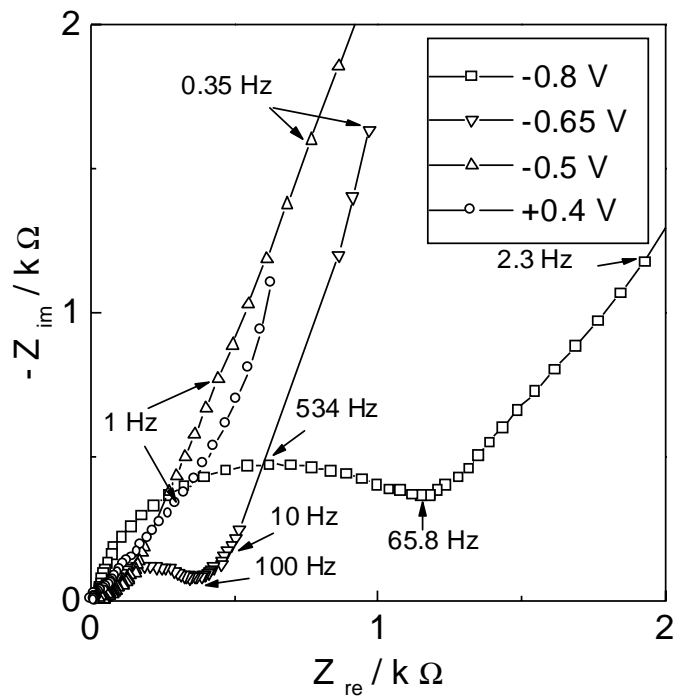

Figure 2. Impedance spectra of a PPy-DS film in the dark $(\mathrm{J}=0.1$ $\mathrm{mA} \mathrm{cm}-2$ and $\mathrm{Q}=190 \mathrm{mC} \mathrm{cm}^{-2}$ ), polarized at $-0.8 ;-0.65 ;-0.5$ and $+0.4 \mathrm{~V}$ vs SCE.

and

$\mathrm{R}_{\text {low }}=\mathrm{R}_{\mathrm{S}}+\frac{\mathrm{R}_{\Sigma}}{3}$

with

$\mathrm{R}_{\Sigma}=\mathrm{R}_{\mathrm{E}}+\mathrm{R}_{\mathrm{I}}$

We calculated RE and RI for our oxidised samples and the results are in Table 2 . The $\mathrm{R}_{\mathrm{S}}=9 \Omega$ was determined in a system without the polymeric film, polarised at $+0.4 \mathrm{~V}^{16}$.

Table 2. Electronic $\left(\mathrm{R}_{\mathrm{E}}\right)$ and ionic $\left(\mathrm{R}_{\mathrm{I}}\right)$ resistances calculated for PPy-DS samples obtained in different synthesis conditions.

\begin{tabular}{cccc}
\hline Film & E/V $v s$ SCE & $\mathrm{R}_{\mathrm{E}} / \Omega$ & $\mathrm{R}_{\mathrm{I}} / \Omega$ \\
1 & +0.3 & 204 & 4200 \\
1 & +0.4 & 173 & 7790 \\
2 & +0.3 & 27 & 5190 \\
2 & +0.4 & 34 & 10500 \\
3 & +0.3 & 3 & 940 \\
4 & +0.4 & 3 & 1000 \\
\hline
\end{tabular}

The diffusion coefficient for the ionic transport in the polymeric matrix can be obtained with the impedance measurements at low and medium frequencies. At the Warburg section the impedance module is described by Eq. 5. The limiting capacitance values $\mathrm{C}_{\mathrm{L}}$ are related to a limiting resistance $\mathrm{R}_{\mathrm{L}}$ when the impedance measurements are extended to sufficiently low frequencies at which the limited film thickness effect can be observed as a charge limitation (Eq. 6). In the complex plane it appears as a vertical line (phase angle $=\pi / 2$ ). In this case $C_{L}$ can be calculated with Eq. 7.

$$
\begin{aligned}
& |Z|=\frac{C_{L}^{-1} \cdot L}{D^{1 / 2} \cdot \omega^{1 / 2}} \\
& C_{L}=\frac{L^{2}}{3 \cdot D \cdot R_{L}} \\
& C_{L}^{-1}=\frac{d\left(-Z_{\text {im }}\right)}{d\left(\omega^{-1}\right)}
\end{aligned}
$$

For the two thicker films the values of diffusion coefficient calculated with Eqs. 5 and 7 are $\mathrm{D}=2.3 \times 10^{-9}(\mathrm{~F} 3)$ and $\mathrm{D}=7.8$ $\mathrm{x} 10^{-9} \mathrm{~cm}^{2} \mathrm{~s}^{-1}(\mathrm{~F} 4)$. When we use the direct determination of RL (Eqs. 5 and 6), these values of $D$ are respectively $4.5 \times 10^{-9}$ and $1.8 \times 10^{-8} \mathrm{~cm}^{2} \mathrm{~s}^{-1}$. The determination of $\mathrm{D}$ by ciclic voltammetry experiments gave $7.9 \times 10^{-9} \mathrm{~cm}^{2} \mathrm{~s}^{-1}$ for a film synthesised in the same conditions of F4 in good agreement with the impedance results. Thickness and morphology effects can explain the difference of D between films F3 and F4.

\section{Effect of the synthesis conditions}

Scanning micrographs (Figure 3) show the effect of charge density on the surface morphology of films of PpyDS from galvanostatic synthesis. It is known that thicker films are superficially most irregular than the thinner ones $17-21$. In the first synthesis stages the polymer is more compact and our results are in accordance with them. Another series of micrographs shows that the current density of synthesis have a pronounced effect over the superficial morphology too (Figure 4). In terms of reproducibility of electrochemical properties and conductivity the best synthesis currents are 4 to $6 \mathrm{~mA} \mathrm{~cm}^{-2} 22$. We observe that lower current densities promote the formation of globules, scales and dendrites with the presence of a large number of pores. Peres and cols. 18 attributed morphology alterations to different lengths of the conjugated polymer chains and to the crystallinity degree of the material. Thickness measurements agree with the observation that those films synthesised with higher current densities are more compact than those obtained with lower ones (Table 1).

\section{Reduced PPy}

For the reduced films $(-0.8<\mathrm{E}<-0.5 \mathrm{~V}$ vs SCE) the effect of the illumination could be observed in different frequency ranges, depending on the applied potential, thickness and morphology of the films. In order to observe if the illumination effect is reversible we performed ten measurements at the same potential $(-0.8 \mathrm{~V})$ alternating dark and illuminated cycles. A plot in the complex plane showing the results of a film synthesised with $\mathrm{Q}=190 \mathrm{mC} \mathrm{cm}^{-2}$ and $\mathrm{J}=0.1 \mathrm{~mA} \mathrm{~cm}^{-2}$ 


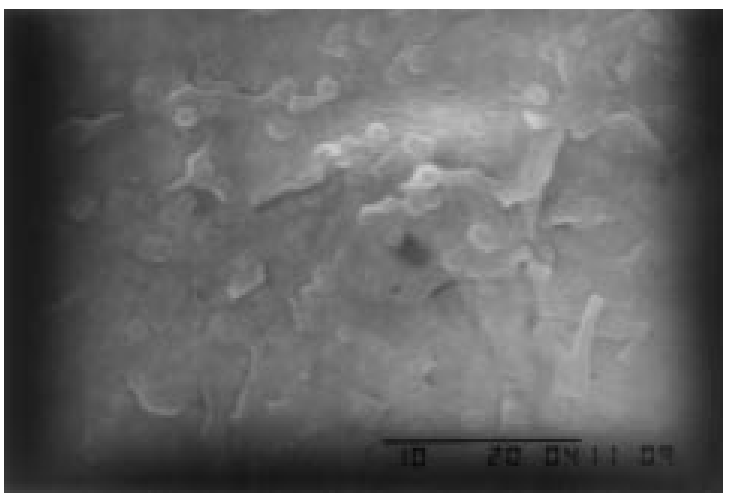

(a)

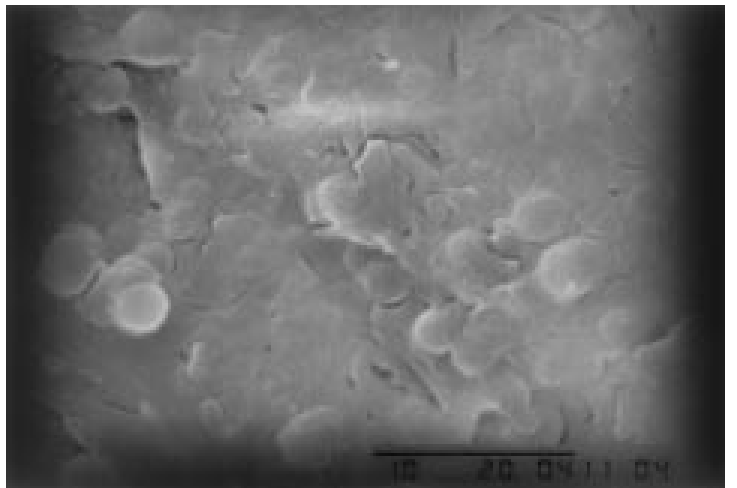

(b)

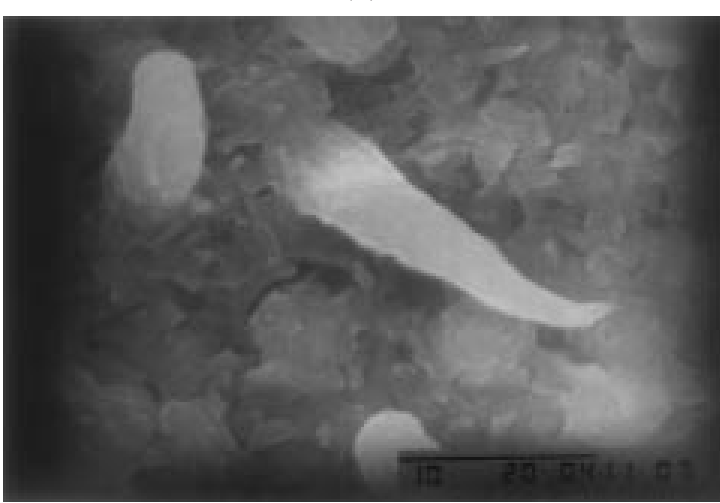

(c)

Figure 3. Scanning micrographies of PPy-DS films synthesised with synthesis current density $\mathrm{J}=1.0 \mathrm{~mA} \mathrm{~cm}-2$ and charges $\mathrm{Q}=290$ (a), 600 (b) and $1200 \mathrm{mC} \mathrm{cm}-2$ (c). Bar $=10 \mathrm{~mm}$

can be seen in Figure 5. In all cases we could confirm the illumination effect as a generalised decrease of the impedance module, with a strong effect over all frequencies of the experiments.

We propose an equivalent circuit to fit our results (Figure 6) that contains an uncompensated resistance $\mathrm{R}_{\mathrm{S}}$, a sub-circuit that consists of the PPy-DS | Electrolyte interface and other sub-circuit related to the Pt |PPy-DS interface. This circuit is derived from the one proposed by Waller and Compton ${ }^{8}$, but in our case we have added a constant phase element, CPE, related to the Warburg element that is

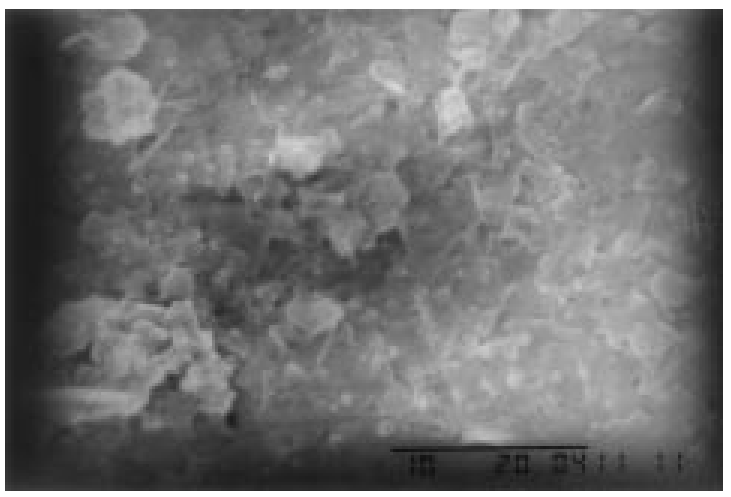

(a)

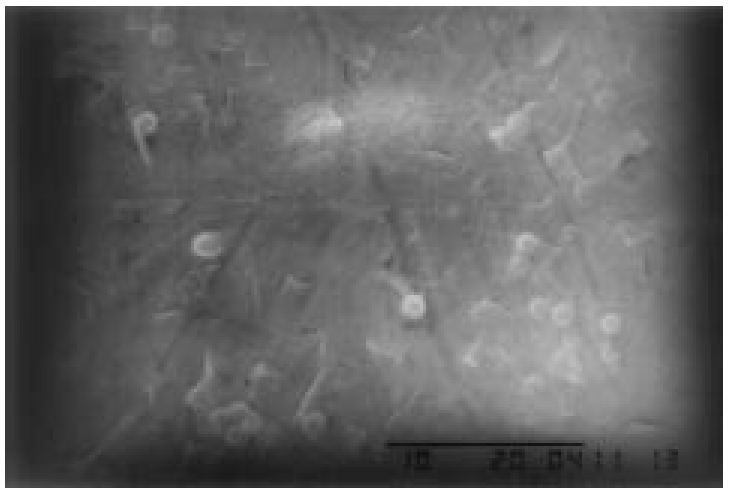

(b)

Figure 4. Scanning micrographies of PPy-DS films synthesised with charge density $\mathrm{Q}=290 \mathrm{mC} \mathrm{\textrm {cm } ^ { - 2 }}$ and current densities $\mathrm{J}=0.1$ (a) and 5.0 (b) $\mathrm{mA} \mathrm{cm}^{-2}$. Bar $=10 \mu \mathrm{m}$.

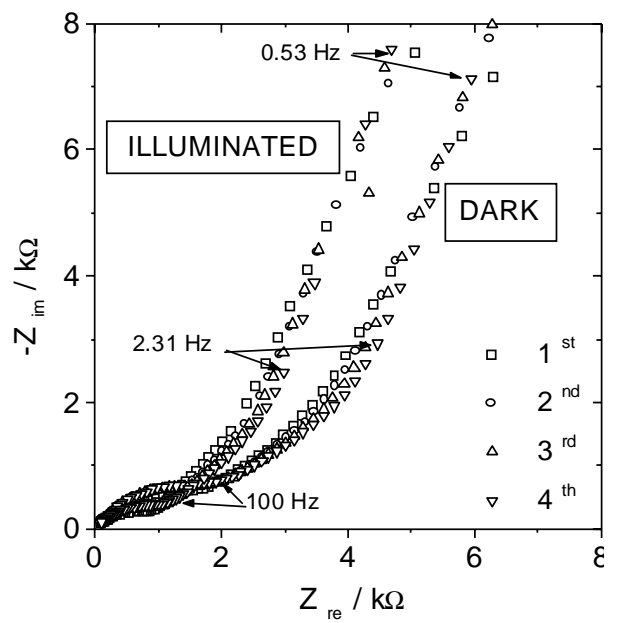

Figure 5. Complex plane plots of eight impedance measurements $(0.5$ $\mathrm{Hz}<\mathrm{f}<65 \mathrm{kHz})$ in a reduced PPy-DS film $\left(\mathrm{Q}=190 \mathrm{mC} \mathrm{cm}^{-2}, \mathrm{~J}=0.1\right.$ $\mathrm{mA} \mathrm{cm}-2$ ) alternately in the dark and under polychromatic illumination $\left(44 \mathrm{~mW} \mathrm{~cm}^{-2}\right)$. The measurements were obtained after $12 \mathrm{~h}$ of film immersion in the electrolyte and $1 \mathrm{~h}$ of polarization at $-0.8 \mathrm{~V}$ vs SCE.

responsible for the difusional part of the impedance spectra of the thicker films. The CPE is a general element represented by a general dispersion formula in admittance (Eq. 8) in which $-1 \leq n \leq 1$. For $n=0$ the $\mathrm{CPE}^{13}$ represents a 
resistance with $\mathrm{R}=\mathrm{Y}_{0}{ }^{-1}$; for $\mathrm{n}=1$ a capacitance with $\mathrm{C}=$ $\mathrm{Y}_{0}$; for $\mathrm{n}=1 / 2$ a Warburg element, and for $\mathrm{n}=-1$ an indutance with $\mathrm{L}=\mathrm{Y}_{0}^{-1}$.

$$
Y^{*}(\omega)=Y_{0}(j \omega)^{n}=Y_{0} \omega^{n} \cos \left(\frac{n \pi}{2}\right)+j Y_{0} \omega^{n} \operatorname{sen}\left(\frac{n \pi}{2}\right)
$$

In Table 3 we show the values of the circuit elements calculated for two representative measurements (up triangle) of Figure 5.

Table 3. Calculated elements of the proposed equivalent circuit for the $3^{\text {rd }}$ set of measurements of Figure 5.

\begin{tabular}{ccc}
\hline Circuit element & Dark & Illuminated \\
\hline $\mathrm{R}_{\mathrm{S}}$ & $26 \pm 4$ & $21 \pm 2$ \\
$\mathrm{R}_{1}$ & $2.3 \pm 0.1 \times 10^{3}$ & $1.2 \pm 0.1 \times 10^{3}$ \\
$\mathrm{CPE}_{1}$ & $3.2 \pm 0.2$ & $5.2 \pm 0.3$ \\
$\mathrm{n}_{1}$ & $0.60 \pm 0.01$ & $0.55 \pm 0.01$ \\
$\mathrm{CPE}_{2}$ & $17 \pm 7$ & $38 \pm 1$ \\
$\mathrm{n}_{2}$ & $0.83 \pm 0.10$ & $0.68 \pm 0.01$ \\
$\mathrm{R}_{2}$ & $3.0 \pm 0.9 \times 10^{3}$ & $6.0 \pm 0.5 \times 10^{3}$ \\
$\mathrm{CPE}_{3}$ & $40 \pm 8$ & $12 \pm 1$ \\
$\mathrm{n}_{3}$ & $0.77 \pm 0.02$ & $0.97 \pm 0.02$ \\
\hline
\end{tabular}

$\mathrm{R} / \Omega ; \mathrm{CPE} / 10^{6}$ mho

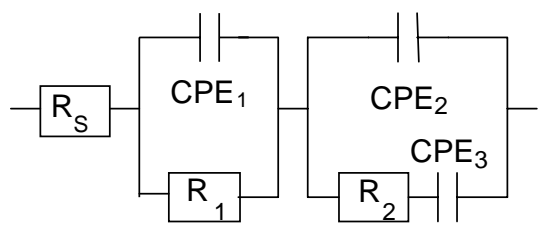

Figure 6. Equivalent circuit used to fit the impedance results. Rs = uncompensated resistance; $\mathrm{R}_{1} / / \mathrm{CPE}_{1}=$ polymer $\mid$ electrolyte interface; $\mathrm{R}_{2} / / \mathrm{CPE}_{2}=$ polymer $\mid$ electrode interface; $\mathrm{CPE}_{3}=$ difusional control element.

The film porosity affects the impedance responses due to relations between favoured interfaces when the polymer is in its oxidised or reduced form. Neutral PPy is less conductive, thus the electrode | polymer and electrode | electrolyte interfaces are the most important ones. In this case the charge transfer resistance is high and can control the impedance response. Thus, the diffusional phenomena are visible only in the spectra of the thicker films. If the film is very porous, the surface of the electrode / electrolyte interface is larger relatively to the electrode | polymer interface, then in appropriate conditions the charge transfer between the metal and the electrolyte is favoured.

An electrode | polymer interface can be present in conditions of a space charge formation, as in the case of semiconductor thin films. If the time constants of charge transfers between the polymer and the electrode, and between the polymer and the electrolyte, are sufficiently apart we can observe a second distinct semicircle at very high frequencies.
Throughout the calculated time constants of our films we can assign one sub-circuit $\left(\mathrm{R}_{1} / / \mathrm{CPE}_{1}\right)$ to the polymer | electrolyte interface and the other $\left(\mathrm{R}_{2} / / \mathrm{CPE}_{2}\right)$ to the electrode | polymer interface. $R_{1}$ is related to: a) an electronic charge transfer resistance during the photoelectrochemical process and/or b) an ionic charge transfer resistance associated to the redox process of the polymer. $\mathrm{CPE}_{1}$ is then related to: a) the space charge capacitance and/or b) the contra-ion accumulation at the polymer | electrolyte interface. $\mathrm{R}_{2}$ corresponds to the electronic charge transfer at the electrode $\mid$ polymer interface and the $\mathrm{CPE}_{2}$ element is associated to the double layer capacitance at this interface. The $\mathrm{CPE}_{3}$ element corresponds to a Warburg element, responsible for the diffusional control of the system. This is reinforced by the observation of the spectra obtained for the thinner films (Figure 7), where no Warburg section is present. The phase and module values are modified at $\mathrm{f}<$ $100 \mathrm{~Hz}$, but the kinetic part is not affected. The thicker films fits have a good quality over all frequencies range, as it can be observed in a Bode plot (Figure 8). In this graph the calculated impedance (lines) have a good agreement with the measured module and phase angle.

Meanwhile, in the full range of measured frequencies, the phase and module values of the impedance are dependent of the morphology of the films, controlled by the synthesis charge density (Figure 9-a). Significant alterations in the kinetic and diffusional parameters of the system constituted by the thinner films are observed. The film obtained with $\mathrm{J}=0.1 \mathrm{~mA} \mathrm{~cm}^{-2}$ (less dense, higher free volume) offers smaller internal resistance, probably because of the polymer chains organisation and bigger conjugation length due the slow synthesis. The bigger conjugation length avoids interchain hopping and diminishes the internal resistance. With the increasing time of imersion of the film in the solution, and after a oxidation / reduction cycle, the kinetic part of the impedance response of the two thinner films become comparable, while the intermediary frequencies regions of the spectrum remains dependent on the film morphology (Figure 9-b). For the thicker films we observe an inversion of this trend, as the internal resistance of the films grows and the interface polymer | electrolyte becomes more important (Figure 10).

The circuit elements were calculated for the four films polarised at - $0.8 \mathrm{~V}$ vs SCE in the dark and under polychromatic illumination ( $44 \mathrm{~mW} \mathrm{~cm}^{-2}$ at the film position) after $12 \mathrm{~h}$ of immersion in the electrolyte. The results are shown in Figure 11, with the various elements values as a function of the polarisation time. The measurements at this potential were initiated at $\mathrm{t}=0$ without illumination. At $\mathrm{t}=0.5$ another measurement was made at the same potential, but the film was illuminated. The same procedure was repeated 


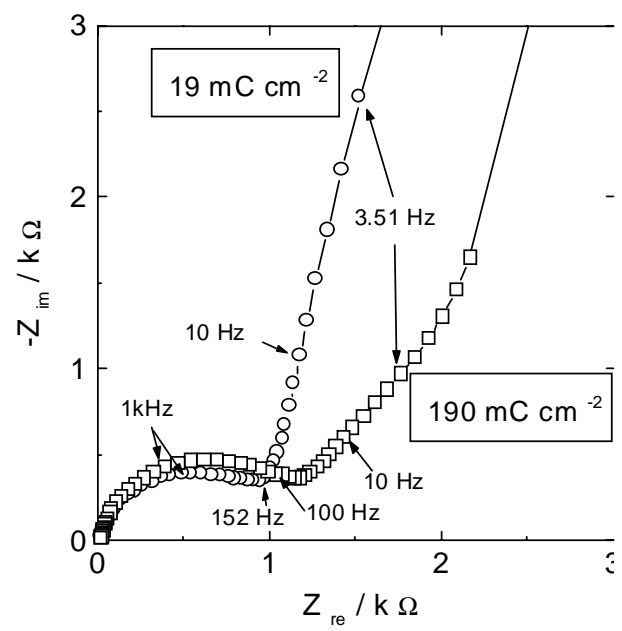

Figure 7. Complex plane plots of impedance obtained for PPy-DS films synthesised with $\mathrm{J}=1.0 \mathrm{~mA} \mathrm{~cm}-2$ and $\mathrm{Q}=19$ and $190 \mathrm{mC} \mathrm{cm}^{-2}$, polarised at $-0.8 \mathrm{~V}$ vs SCE.

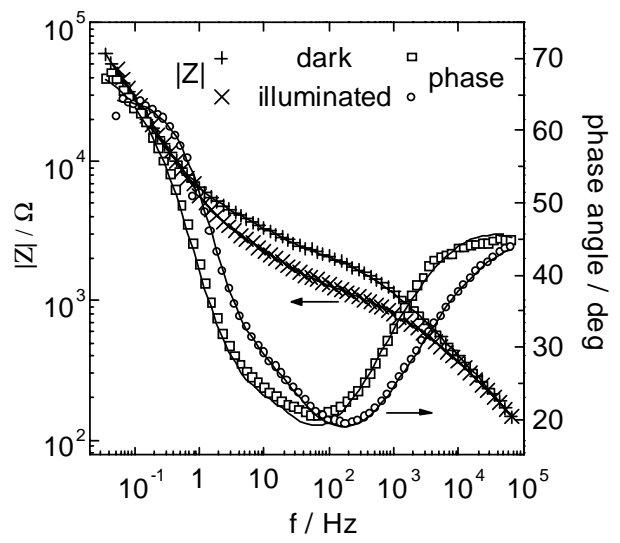

Figure 8. a) Bode plot containing measured (symbols) and calculated (lines) module and phase angles for a PPy-DS thick film (Q $=190$ $\mathrm{mC}, \mathrm{J}=0.1 \mathrm{~mA}$ ), polarised at $-0.8 \mathrm{~V}$ vs SCE, in the dark ( $\square$ )and under illumination $(\mathrm{O})$. b) calculated circuit elements.

maintaining the applied potential but alternating dark $(\mathrm{t}=1$; $2 ; 3$ and $4 \mathrm{~h}$ ) and illumination $(\mathrm{t}=1.5 ; 2.5 ; 3.5$ and $4.5 \mathrm{~h})$ conditions. For the thinner films the relative errors of the fittings are high. It was not possible to obtain good correlations using the proposed circuit of Figure 6, probably due to the absence of diffusional limitations of the impedance. For the thicker ones we note a systematic variation of the calculated circuit elements in exception to the $\mathrm{CPE}_{1}$. The film synthesised with $0.1 \mathrm{~mA} \mathrm{~cm}^{-2}$, less dense, requires $1 \mathrm{~h}$ of polarization at $-0.8 \mathrm{~V}$ until the values of CPE's and R's estabilize. In contrast, the denser film synthesised with 1.0 $\mathrm{mA} \mathrm{cm}-2$ require $2 \mathrm{~h}$ until the values of the calculated elements beginn to be reversibly affected by the illumination.

Summarising, we have shown that the interfaces that control the charge transfer are: $\mathrm{Pt} \mid$ Electrolyte, which determines the ohmic response of the system, Pt|PPy, which can present a space charge region with the presence of a

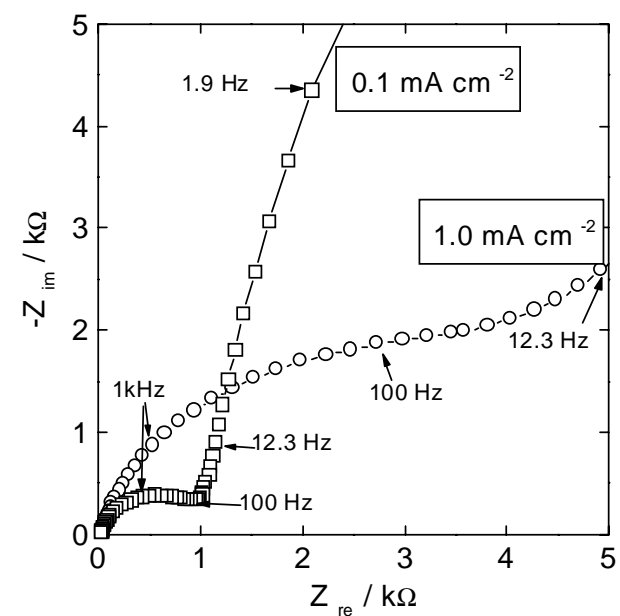

(a)

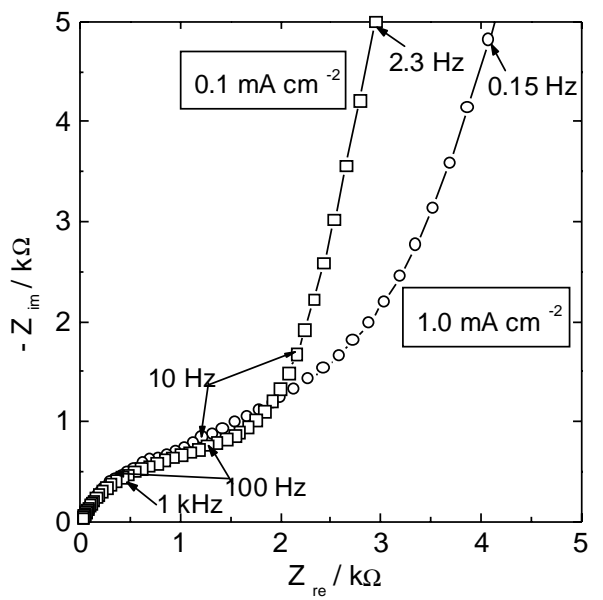

(b)

Figure 9. Complex plane plots of impedance obtained for PPy-DS films synthesised with $\mathrm{Q}=19 \mathrm{mC} \mathrm{cm}-2$ and $\mathrm{J}=0.1$ and $1.0 \mathrm{~mA} \mathrm{~cm}$ 2 , polarised at $-0.8 \mathrm{~V}$ vs SCE. a) initial; b) after $12 \mathrm{~h}$ of immersion in the electrolyte.

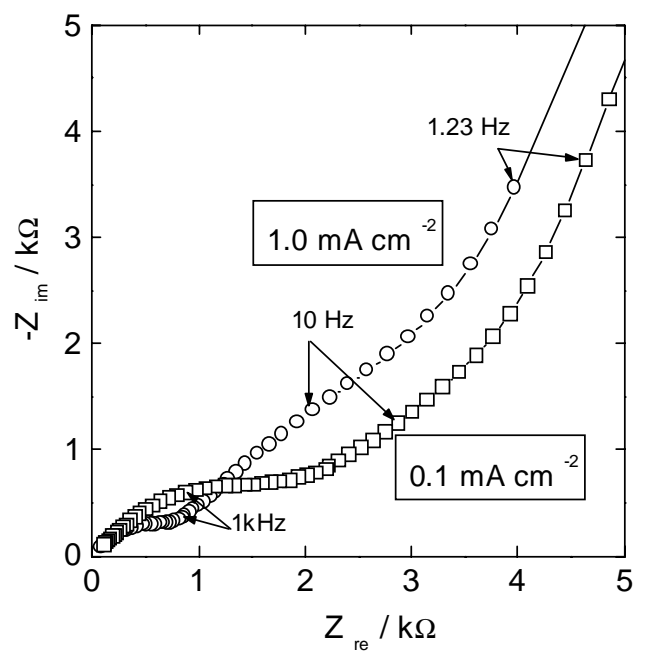

Figure 10. Impedance complex plane plots obtained for PPy-DS films synthesised with $\mathrm{Q}=190 \mathrm{mC} \mathrm{cm}^{-2}$ and $\mathrm{J}=0.1$ and $1.0 \mathrm{~mA} \mathrm{~cm}-2$, polarised at $-0.8 \mathrm{~V}$ vs SCE. 

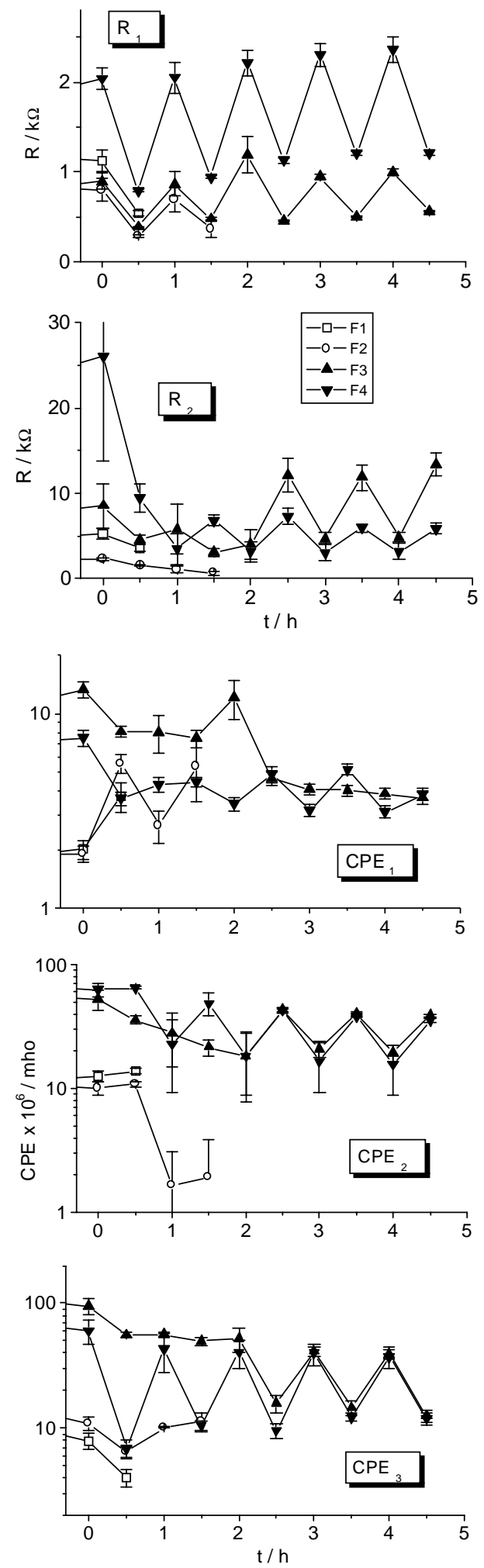

Figure 11. Elements of the proposed circuit calculated for the films polarised for $5 \mathrm{~h}$ at $-0.8 \mathrm{~V}$ vs SCE, alternating dark $(0 ; 1 ; 2 ; 3$ and $4 \mathrm{~h})$ and illumination $(0.5 ; 1.5 ; 2.5 ; 3.5$ and $4.5 \mathrm{~h})$ conditions. The PPyDS films synthesised at $\mathrm{Q}=19 \mathrm{mC}$ and $\mathrm{J} 1.0 \mathrm{~mA}(-\square-) ; \mathrm{Q}=19 \mathrm{mC}$ and $\mathrm{J}=0.1 \mathrm{~mA}\left(-\mathrm{O}_{-}\right) ; \mathrm{Q}=190 \mathrm{mC}$ and $\mathrm{J}=1.0 \mathrm{~mA}\left(\mathbf{-}^{-}\right)$and $\mathrm{Q}=190 \mathrm{mC}$ and $\mathrm{J}=0.1 \mathrm{~mA}\left(-\nabla^{-)}\right.$were previously immersed in the electrolyte for $12 \mathrm{~h}$ before the beginning of the measurements. space charge capacitance at very high frequencies and PPy $\mid$ Electrolyte, with the formation of double layers and the presence of double layer capacitances at high frequencies. These interfaces are not well defined because of the swelling of the films and of the presence of morphological alterations in function of their thickness. Besides, the bulk of the material can contribute to the total impedance due to the presence of a diffusional control of the ions through the polymer matrix characterised by the Warburg section at intermediary frequencies and the charge accumulation at very low frequencies, characterised by the limiting or geometric capacitance of the film. The effect of the illumination of films synthesised with different thicknesses and morphologies could be observed through Electrochemical Impedance measurements.

\section{Acknowledgements}

DAAD and FAPESP (97/03968-1) are acknowledged for fellowships and FAPESP (96/09983-6) for financial support.

\section{References}

1. Neves, S.; Polo da Fonseca, C. N.; De Paoli, M.-A. Synth. Met. 1997, 89, 167.

2. Micaroni, L.; Fonseca, C. N. P.; Decker, F.; De Paoli, M. -A. Solar Energy Matter. Sollar Cells 2000, 60, 27.

3. Martini, M.; De Paoli, M. -A. Solar Energy Matter. Sollar Cells 2000, 60, 73.

4. Bull, R. A.; Fan, F. -R. F; Bard, A.J. J. Electrochem. Soc. 1982, 129, 1009.

5. Rubinstein, I.; Sabatini, E.; Risphon, J. J. Electrochem. Soc. 1987, 134, 3078.

6. Albery, W. J.; Mount, A. R. J. Electroanal. Chem. 1991, 305, 3.

7. Feldberg, S. W. J. Am. Chem. Soc. 1984, 106, 4671.

8. Waller, A. M.; Compton, R. G. J. Chem. Soc., Faraday Trans. 1989, 1, 977.

9. Naoi, K.; Osaka, T. J. Electrochem. Soc. 1984, 134, 2479.

10. Naoi, K.; Oura, Y.; Maeda, M.; Nakamura, S. J. Electrochem. Soc. 1995, 142, 417.

11. Otero, T. F.; Angulo, E. Synth.Met.1992, 51, 87.

12. Deslouis, C.; El Moustafid, T.; Musiani, M. M.; Tribolet, B. Electrochim. Acta 1996, 41, 1343.

13. Boukamp, B.A. Equivalent Circuit Users Manual, EQUIVCRT, University of Twente, Holland, 1988.

14. Martini, M.; De Paoli, M.-A. Solar En. Mater. Solar Cells, in press.

15. Albery, W. J.; Chen, Z.; Horrocks, B. R.; Mount, A. R.; Wilson, P. J.; Bloor, D.; Monkman, A. T.; Elliott, C. M. 
Faraday Discuss. Chem. Soc. 1989, 88, 247.

16. Pickup, P. G. J. Chem. Soc., Faraday Trans. 1990 , 86(21), 3631.

17. De Paoli, M. -A.; Peres, R. C. D.; Pernaut, J. -M.; J. Braz. Chem. Soc. 1990, 1, 50.

18. Peres, R. C. D.; Pernaut, J. -M.; De Paoli, M. -A. J. Polym. Sci. (A): Polym. Chem. 1991, 29, 225.
19. Naoi, K.; Oura, Y.; Maeda, M.; Nakamura, S. J. Electrochem. Soc. 1995, 142, 417.

20. Warren, L. F.; Anderson, D. P. J. Electrochem. Soc., Electrochem. Sci. Tech. 1987, 134, 101.

21. Hahn, S. J. Electron. Mater. 1986, 15, 145.

22. Pernaut, J. -M.; Peres, R. C. D.; Juliano, V. F.; De Paoli, M. -A. J. Electroanal. Chem. 1989, 274, 225.

Received: June 16, 1999

FAPESP helped in meeting the publication costs of this article. 